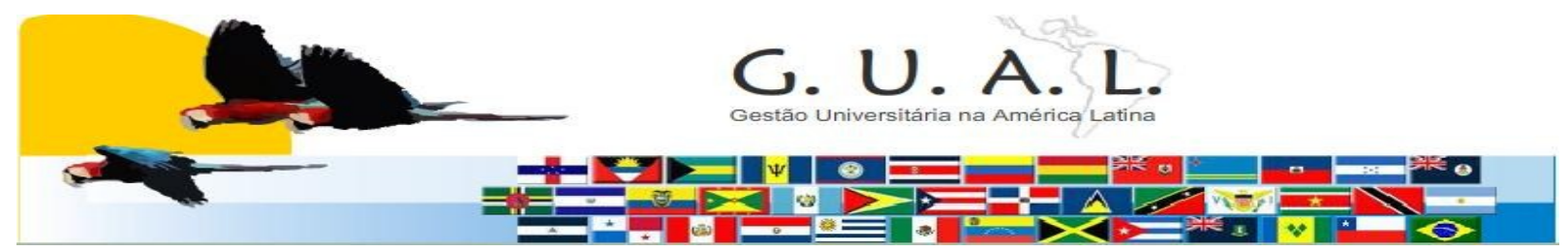

ISSN 1983-4535

\title{
GESTÃO DE PESSOAS E DE INSTITUIÇÕES DE ENSINO: UM EXERCÍCIO DE SOMA POSITIVA
}

\author{
Marlon Jackson Tafner, Doutor \\ Associação Educacional Leonardo da Vinci - UNIASSELVI \\ marlon@grupouniasselvi.com.br \\ Everaldo da Silva, Doutor \\ Associação Educacional Leonardo da Vinci - UNIASSELVI \\ evesociologia@gmail.com
}

\begin{abstract}
RESUMO
Para muitos, ganhar representa a perda dos outros. Isso significa que duas ou mais partes competem numa base fixa em que o vencedor fica com a melhor parte. Esse tipo de relações é caracterizado por ser rígido, baseado no preço, e não no valor. São, desse modo, relações adversas e não promovem o desenvolvimento das partes. Este artigo explora as várias formas de abordagem do relacionamento entre organizações e, inevitavelmente, entre pessoas, procurando adotar uma abordagem diferente da seguida pelos investigadores, acadêmicos e praticantes quando se debruçam sobre as relações win-win entre organizações. A consideração de aspectos resultantes das ciências humanas, combinada com o que de melhor as tradicionais abordagens têm para oferecer, pode revelar-se muito importante e renovadora no estabelecimento e na manutenção de relações win-win.
\end{abstract}

Palavras-chave: Gestão. Educação superior. Relação win-win. Homem parentético. 


\section{INTRODUÇÃO}

Na concepção do sociólogo Alberto Guerreiro Ramos, sobre a sociedade, as pessoas deveriam unir-se em grupos naturalmente pela comunhão, e não pelo interesse. (RAMOS, 1984). Ramos tinha um pensamento conservador, valorizava a cultura e a moral do homem, criticando a sociedade moderna que torna as pessoas extremamente utilitaristas, fúteis e egoístas.

Muito se tem escrito e discutido sobre gestão, na atmosfera de crise em que se vive. Além disso, o envolvimento das organizações contemporâneas acaba por se refletir nas teorias já desenvolvidas sobre a gestão e, tanto no campo profissional como no acadêmico, os indivíduos vivenciam progressivamente essa crise no seu dia a dia.

Igualmente se vive no descaso diante de todas as formas de desvirtuamento que caracterizam a sociedade moderna, com excessiva riqueza e muita miséria, com possibilidades de paz e uma realidade de guerra. Um limiar de século marcado por famílias sem terra, sem teto, sem alimento, sem direito ao estudo e, principalmente, sem emprego. São dificuldades assim caracterizadas por Furtado (1999, p. 34): "Em nenhum momento da história foi tão grande a distância entre o que somos e o que esperávamos ser.”

Nesse contexto, o ambiente interno e externo das instituições é, atualmente, influenciado por um elevado grau de falta de clareza e confusão. Nesse sentido, diversos estudiosos concluíram que está surgindo um novo modelo de homem cujo desenvolvimento e esclarecimento são essenciais para ultrapassar o estado crítico da arte e da teoria da administração. James Carroll, por exemplo, vê uma "conscientização crescente" que está "transbordando e inundando [...] os sistemas sociais existentes". O autor também revela o surgimento de um novo tipo de personalidade que não mais "se ajusta facilmente à estrutura de valores organizacionais e institucionais baseada em percepções e interesses previamente fixados." (CARROLL, 1969, p. 493).

As orientações propostas por Carroll estão baseadas na ideia de que se necessita de um ponto de referência para desenvolver algum senso de direção no trato com os problemas administrativos, haja vista que tipos de circunstâncias sociais contemporâneas estão afetando cada indivíduo e as organizações.

Neste limiar de século XXI, alguns temas, como mudança, multiprofissões, mobilidade, saber se relacionar, autogestão, ansiedade e gestão, são cada vez mais debatidos e teorizados. 
E a gestão educacional, como se encontra? Muitas empresas ainda mantêm uma gestão mecanicista, em que as competências sociais, a comunicação e o relacionamento interpessoal não aparecem.

Vale lembrar que a gestão está comumente relacionada à administração, não na esfera pública, mas no setor privado, onde o foco está nas exigências do mercado. Não obstante, se veem, ainda, alguns pronunciamentos contrários a um possível elo entre educação e negócio. Ressalta-se, porém, que, de maneira alguma, se está afirmando que se deve vulgarizar a educação, mas que "[...] fortalecer o setor para que este tenha condições de manter-se focado em sua vocação, que é o ensino, mas com o desempenho necessário para manter-se vivo" reúne condições para uma gestão moderna. (STEINBERG; MARCATTI, 2010, p. 267).

O que se defende é que uma organização de ensino seja capaz de promover continuamente a melhor formação de seu corpo docente, mestres e pesquisadores, porém estando atualizado com todo o arsenal acadêmico e estrutural indispensável à preparação de seus alunos. (STEINBERG; MARCATTI, 2010, p. 267).

Na educação superior, as instituições universitárias devem ter programas contínuos para formação de gestores com perfil de liderança, porque, com a diversidade de gerações que se tem nos ambientes de trabalho, é tangível a necessidade de encontrar líderes capacitados para gerir equipes com um leque de diversidade, principalmente formadas pelos baby boomer, geração X e geração $\mathrm{Y}$.

A busca pelo sucesso é constante no mundo do trabalho, mas não é um dom natural, algo que possa ter uma receita pronta e aplicável. Tem-se, sim, que ouvir dicas, compreender os exemplos e habilidades executivas desenvolvidas pelos profissionais de sucesso ao longo de suas carreiras.

A profissionalização de gestores é primordial para que a gestão educacional esteja focada no compromisso da missão da instituição, bem como nas demandas que a sociedade exige, principalmente, na qualidade do ensino e no saber-fazer.

O presente trabalho é, indiscutivelmente, limitado. O objetivo é, apenas, debater a gestão de pessoas nas instituições de ensino. Ainda neste ensaio teórico, discutem-se conceitos importantes, como o da destruição criadora, do economista Joseph Schumpeter, e de modelos de homem, do renomado sociólogo Alberto Guerreiro Ramos, remetendo à relação win-win nas organizações. 


\section{A EDUCAÇÃO SUPERIOR E A DESTRUÇÃO CRIADORA}

O economista austro-americano Joseph Schumpeter afirma que o capitalismo se desenvolvia em razão de sempre estimular o surgimento dos empreendedores, isto é, de capitalistas ou inventores extremamente criativos, os inovadores, que quase sempre despontavam em grupos e eram os responsáveis por todas as ondas de prosperidade que o sistema conhecia. (SCHUMPETER, 1982).

No início, o capitalismo era concorrente, e o papel do empresário inovador confundia-se com o capitalista que gerava o inusitado, podendo haver o lançamento de um novo produto que não existia antes no mercado, como, por exemplo, o telefone ou o automóvel, uma nova técnica de produzir, como fordismo ou taylorismo, a descoberta de uma nova matéria-prima, ou a conquista de outro mercado ainda não explorado.

A partir do momento em que se iniciava uma situação nova, essa acabava provocando uma onda geral de mudanças. Primeiramente, aquele que ousava acabava sendo compensado por enormes lucros, estabelecendo o que Schumpeter determinou como lucro do monopólio, que, aos poucos, diminuía quando outros empreendedores exploravam a ideia inovadora.

Sob a ótica de Schumpeter (1982), toda inovação implica numa destruição criadora. O novo não nasce do velho, mas surge próximo a ele e tende a superá-lo. Entre vários exemplos, temos a invenção do transporte a vapor, dos trens e dos navios, que fizeram sumir a vasta rede que existia de diligências, de carruagens, de clippers e demais embarcações a vela. Hoje, há a informática e a robotização que estão fazendo desaparecer milhares de postos de trabalho. Também no século XIX, a adoção dos teares mecânicos na indústria têxtil, primeiro, na Inglaterra e, depois, em grande parte da Europa, danificou o trabalho artesanal de milhares de famílias.

Tem-se uma significativa alteração na fase do denominado capitalismo trustificado (monopolista). Há um rompimento entre o papel do capitalista e do empreendedor. O inovador não é mais o proprietário, mas se contrata alguém para elaborar os futuros projetos de transformação. Hoje, o capitalista é quem reúne a mão de obra altamente qualificada, e a inovação processa-se em laboratórios especiais de cientistas e pesquisadores, que são os novos agentes do desenvolvimento econômico.

Quando há uma exaustão dos efeitos de inovação, ou seja, quando um novo produto chega ao seu limite extremo do mercado, ficando saturado, os lucros declinam, gerando uma 
reação negativa na cadeia, fazendo os negócios refluírem. Nunca se sabe quanto tempo permanece um período desses, quase sempre inflacionário, mas Schumpeter (1982) afirma que esse comportamento da economia capitalista é cíclico. Segundo o autor, o processo de estagnação somente será interrompido quando outra inovação chegar ao mercado, dando um novo impulso à retomada do crescimento.

No caso, o que se viu, na educação superior em particular, foi uma verdadeira transformação econômica em várias regiões do Brasil a partir da década de 1990, principalmente no período do governo do ex-presidente Fernando Henrique Cardoso.

As regiões Norte e Centro-Oeste foram as que mais evoluíram no número de alunos matriculados proporcionalmente em relação ao período de 1991 a 2002. Embora a região Norte represente, do total, 14,8 por cento, em 2002, e a Centro-Oeste, 24,2 por cento também em 2002, nesses 11 anos, a Região Norte evoluiu 266,86 por cento e a Região Centro-Oeste, 230,29 por cento. A terceira que mais cresceu foi a Região Sul, com 135,54 por cento, seguida da Região Nordeste, com 119,44 por cento, e da Região Sudeste, com 98,34 por cento. (SILVA, 2010, p. 158).

Qualquer região pode experimentar um processo de transformação econômica regional, devido a um avanço combinado entre o aumento do número de pessoas graduadas e a oferta de emprego e também no processo de fusão e aquisição de instituições universitárias. Tal afirmação está fundamentada nas contribuições teóricas de Schumpeter (1982), o qual identificou como sendo vendavais de destruição criativa.

Segundo o presidente da Associação Brasileira de Mantenedoras do Ensino Superior (ABMES) ${ }^{1}$, senhor Gabriel Mario Rodrigues, o mercado de educação superior cresceu muito, e as instituições particulares contribuíram para o desenvolvimento de algumas regiões, consideravelmente as instituições particulares, gerando uma concorrência positiva para o mercado.

Os últimos anos representam a democratização do acesso ao ensino superior. Antes deste período, existiam poucas vagas, que estavam concentradas nas instituições públicas e nos grandes centros. Hoje, todo aluno concluinte pode estudar perto de sua residência, ou numa cidade muito próxima. As IES particulares tiveram um papel decisivo neste processo. (RODRIGUES apud SILVA, 2010, p. 162).

De outra face, não se pode olvidar o fato de que também se tem visto, nos últimos

\footnotetext{
${ }^{1}$ Criada na cidade de Brasília, Distrito Federal, em 30 de agosto de 1982, é uma entidade de direito privado, com personalidade jurídica própria, sem quaisquer finalidades lucrativas, tendo sede e foro na capital da República do Brasil e duração indeterminada.
} 
anos, evasão nas instituições privadas, sendo difícil avaliar o porquê desse fenômeno, bem como se a desistência é, de fato, evasão, dado que a opção de estudar na educação superior ainda é o reflexo da escolha de uma profissão. Isso porque as pessoas optam por um curso e, depois, por considerarem que erraram na escolha, mudam, migrando para outras áreas e, até, outras instituições.

O problema da evasão no Brasil não existe apenas nas particulares; isto também acontece nas públicas e nas escolas do exterior. Se existe um sistema atrelado ao passado esse é o universitário. A metodologia reinante está presa ainda na sala de aula centrada no professor. Os currículos estão condicionados às conhecidas por todos. Falta criatividade e inovação e o aluno não quer mais perder seu tempo com aulas que nada lhe acrescentam. Por isso, com o passar do tempo, quem não inovar não irá prosperar. As leis de mercado não suportam a mediocridade. (RODRIGUES apud SILVA, 2010, p. 162).

Outro aspecto a considerar é que, na contemporaneidade, as pessoas mudam de função com mais facilidade e, por vezes, procuram estudar continuadamente, o que leva muitas delas a optar por começar nos cursos tradicionais, como, por exemplo, Direito, e, depois, migrar para cursos, conforme o mercado de trabalho as encaminha profissionalmente.

Por esse mister, a destruição criativa pode ocorrer com a criação de novas indústrias, como também com profundas mudanças na tecnologia e na organização produtiva, inclusive contribuindo para o crescimento nacional, regional e local. Outrossim, reconstitui e revitaliza as regiões já existentes, afetando diretamente a geração de novas funções e de empregos, ou seja, o mundo do trabalho.

Outro fator importante para o desenvolvimento de algumas regiões e do crescimento da educação superior foi a codependência e interatividade entre as instituições, havendo um alto grau de concentração e integração entre compradores e vendedores, fato que gerou grandes grupos que passaram a dominar o mercado de educação superior no Brasil.

Ademais, a respeito da educação, se vê, ao longo do tempo, que a mesma exerce função cultural, social e histórica importante para o funcionamento da sociedade. A saber, a educação produziu e atendeu aos interesses de diversas culturas. Isso pode ser identificado na Antiguidade, nos tempos medievais e nos tempos modernos, e continua, ainda, no hodierno, com o processo de globalização, passando por inúmeras mudanças, tanto na esfera institucional, quanto pedagógica, curricular, ideológica e de gestão de pessoas.

Com efeito, a destruição criativa notadamente introduz um novo bem, uma nova 
tecnologia ou um novo meio de produção que, peremptoriamente, impacta nas organizações. Por conseguinte, dado o exposto, as instituições necessitam de pessoas, que há um longo tempo e por que não ainda hoje, foram consideradas

como recursos organizacionais, originando-se desse paradigma a denominação de 'recursos humanos'. Como recursos, as organizações que adotam tal concepção os vêem como sujeitos passivos da ação empresarial, necessitando ser controlados e administrados para que possa obter deles o máximo em produtividade. (COLOMBO, 2010, p.179).

Convém evidenciar, também, que as instituições que buscam melhor atuação no seu campo de atuação e no mundo do trabalho privilegiam pessoas como parceiras, tendo, por consequência, um clima interno com motivação, com grau de coletividade intenso, refletindo diretamente no mercado e também influenciando seus concorrentes a mudarem seu status quo.

Os seres humanos trazem idiossincrasias contrárias à racionalidade da organização, não sendo diferente nas instituições de ensino. Dessa forma, é imprescindível dizer que, para submeter a disposição singular do ser humano de pensar seus valores e interesses individuais ao propósito da organização, esta precisa submeter as pessoas a um objetivo comum, e este objetivo acaba não sendo coletivo e democraticamente determinado. Ele é imposto de maneira legítima pela direção da empresa.

Dentro das organizações, muitos indivíduos sobressaem do mais alto grau de racionalização e regulação que alcançam na sociedade da qual participam, não só recebendo prescrita a condução de seus atos e normas reguladas, mas também a sua liberdade de pensamentos e sentimentos permitidos. Igualmente, ainda se encontram, nas instituições universitárias, gestores afirmando que "Não vou investir em meus professores ou funcionários para depois perdê-los para a concorrência." (COLOMBO, 2010, p.181).

Normalmente, se encontram pessoas relatando algum fato ocorrido em uma instituição onde o indivíduo se sente oprimido, tendo sua personalidade não aceita. Esses profissionais geralmente reprimem os traços de sua personalidade, passando a agir como máquinas e, sobretudo, utilizando intensivamente a racionalidade funcional ${ }^{2}$.

Acredita-se que considerar a personalidade do funcionário para direcionar sua carreira resulta, em geral, em bem-estar. Muitas vezes, de tanto a pessoa ter a sua personalidade reprimida, fica bloqueada, anulando seus valores para aceitar a demanda externa, o que gera

\footnotetext{
${ }^{2}$ Não se pergunta pelos seus pressupostos nem pelo seu sentido, agindo na esfera do como, sem se perguntar pelo porquê.
} 
sentimentos, como o de agressividade, acontecendo, nesse caso, o pior: o funcionário acaba sendo reconhecido como um funcionário-problema.

Logo, uma instituição que privilegia a gestão de pessoas difere de uma empresa tradicional capitalista, porque, na primeira, os colaboradores são vistos como patrimônio, sendo que os gestores têm atitudes parentéticas, participando do lucro e dos prejuízos, tendo, pelo menos idealmente, uma estrutura de funcionamento democrática, inserida num ambiente competitivo e burocrático. Daí surge o desafio vivido pelos colaboradores de conciliar a necessidade de manter-se competitivo no mercado com os princípios democráticos e solidários do processo de fortalecer a sociedade por meio das instituições universitárias.

Numa instituição que busca, por exemplo, alto nível de qualidade, os colaboradores não podem ser dispensados, como ocorre numa instituição tradicional, tendo que buscar uma alternativa justa e democrática para resolver a situação, passando, impreterivelmente, pela necessidade de haver um diálogo entre eles, uma vez que grande parte dessas instituições cria comissões formadas pelos próprios colaboradores e gestores para gerir esse tipo de situação. Nesse processo, ocorre uma relação win-win, ao invés do modelo win-lose, junto com atitudes parentéticas e o uso mais intensificado da racionalidade substantiva dentro das organizações.

\section{A RELAÇÃO WIN-WIN E O HOMEM PARENTÉTICO NO MUNDO DO TRABALHO}

Tem-se o entendimento de que o sociólogo Alberto Guerreiro Ramos ${ }^{3}$ procurou reavaliar a evolução da teoria administrativa, usando pontos de referência como modelos de homem, a saber, o homem operacional, o homem reativo e o homem parentético. Durante toda a história do estudo da administração, teóricos e profissionais escreveram e agiram fazendo suposições acríticas a respeito da natureza do homem. Atualmente, porém, uma teoria administrava que não tenha consciência das suas implicações psicológicas dificilmente poderá ser aceita.

Ramos (1984) deixa assentado que, na teoria administrativa, o homem operacional seria o trabalhador passivo, que se deixa programar por especialistas para desenvolver sua função na instituição, ou seja, é um indivíduo que não questiona, é motivado por recompensas materiais e econômicas, não levando em conta os princípios éticos para chegar ao seu objetivo

\footnotetext{
${ }^{3}$ Teve destaque por sua grande relevância política e acadêmica nas ciências sociais no Brasil. É de sua autoria o Projeto n ${ }^{\circ}$ 984/63, apresentado e aprovado na Câmara Federal sobre a profissionalização do Administrador.
} 
final. Por esse mister, faz uso em grande quantidade da racionalidade funcional, que diz respeito a qualquer conduta, acontecimento ou objeto, à medida que esse é reconhecido como apenas um meio de atingir uma determinada meta, solapando a capacidade de sadio julgamento do indivíduo, diminuindo sua aptidão crítica.

Atualmente, não é mais possível legitimar tal racionalidade funcional nas organizações, o que vem provocando questionamentos sobre o valor do homem operacional e de toda sua estrutura.

Em momento posterior, influenciado pelos estudos de Hawthorne ${ }^{4}$, com a Escola de Relações Humanas, teve-se o surgimento do homem reativo. Os humanistas percebiam o trabalhador como "um ser reativo" (RAMOS, 1984), tendo como objetivo principal a adaptação do indivíduo ao contexto de trabalho, e não seu crescimento individual. Segundo Ramos (1984, p. 6),

conceitos de mudança organizacional, por exemplo, são formulados em termos reativos, isto é, testados quando a sua capacidade de responder acriticamente às flutuações de seus ambientes e sem assumir a responsabilidade pelos padrões de qualidade e prioridade desse mesmo ambiente.

A teoria reativa baseia-se em uma visão ingênua da natureza dos insumos e produtos. Considera que os insumos consistem em pessoas, materiais e energia, neutralizando os fatores ético e valorativo do ambiente, cuja racionalidade e legitimidade são simultaneamente ignoradas.

Outro aspecto envolve a integração indivíduo/empresa. Os defensores da integração omitem o caráter básico, duplo da racionalidade. Em outras palavras, existe uma racionalidade cujos padrões nada têm a ver com comportamento administrativo. Trata-se da racionalidade substantiva $^{5}$, que não está necessariamente relacionada a uma coordenação de meios e fins (racionalidade funcional), do ponto de vista da eficiência. Assim, o comportamento que ocorre sob o amparo da racionalidade substantiva pode ser administrativo apenas por acaso, não por necessidade.

A instituição e seus líderes podem julgar se um comportamento é instrumental

\footnotetext{
${ }^{4}$ Consideravam o homem mais complexo do que consideravam os teóricos tradicionais, tendo uma visão mais sofisticada sobre a motivação do ser humano, levando em conta os sentimentos e atitudes.

${ }_{5}$ Os pressupostos e sentido do indivíduo ganham importância, preferindo agir na esfera do "porquê", participando da esfera do "como" apenas por acidente.
} 
(funcional) para suas finalidades, mas nunca sua adequação à racionalidade substantiva, sendo privilégio dessa última julgar a organização. Por exemplo, foi a tensão crônica entre as duas racionalidades que fez com que Julian Assange, fundador do WikiLeaks, divulgasse, em 2011, em cinco jornais do mundo, vários documentos confidenciais dos Estados Unidos.

Finalmente, tem-se o modelo de homem parentético, que tem a capacidade de diminuir as tensões que ocorrem entre o uso da racionalidade funcional e da substantiva no mundo do trabalho. Como resultado, há um indivíduo que participa na organização, mas que está entre "parênteses", ou seja, ele é diferente do modelo reativo e operacional, por ter uma atitude crítica, por buscar a liberdade de pensamento, tendo um comportamento proativo, não aceitando trabalhar numa instituição onde não se privilegiam a criatividade e a capacidade de pensar do colaborador.

Como resultado, tem-se, no homem parentético, um colaborador eticamente comprometido com a missão e a visão da instituição, bem como com seus valores. Inclusive, não é uma pessoa passiva, mas proativa, influenciando o ambiente em que está inserido com valores humanos e com visão sistêmica.

Os 'modelos' organizacionais das IES de sucesso nestas primeiras décadas do século XXI devem ser gerenciados por valores humanos líderes de si mesmos, com visão sistêmica e estratégica, habilitados a lidar com mudanças e a trabalhar em equipe, entre outras habilidades. (CARDIM, 2010, p. 33).

Oportuno se torna dizer que um dos problemas principais a ser considerado na administração global do sistema social é o esboço de novos tipos de organização ou novos padrões de trabalho. Na realidade, se está vivenciando um sistema capaz de reduzir tarefas árduas até o ponto de completa eliminação do trabalho; todavia, muitas pessoas não estão levando em conta essa possibilidade concreta. Por conseguinte, os gestores das organizações,

em todos os níveis, do topo à base, terão melhores recursos em uma organização na qual fluam coerentemente, de forma simples e transparente, os mecanismos e os procedimentos gerenciais. Contudo, a formação desse gestor, o seu perfil profissional, é peça fundamental para o sucesso de qualquer empreendimento. (CARDIM, 2010, p. 34).

Cabe destacar, ainda, que os gestores não devem ignorar a tendência atual de buscar cativar os colaboradores para diminuir o nível de insatisfação no ambiente de trabalho. 
Todo gestor precisa, nesse momento, por meio da reflexão, impulsionar, no ambiente de trabalho, uma relação do saber fazer, aproveitando os recursos previstos e disponíveis na instituição.

É de ser relevado que há, nas organizações, pessoas com pensamentos diferentes e idades diferentes. O gestor, o líder, deve estar atento ao ambiente interno e externo em que a instituição está inserida, respeitando o caminho que ela deseja seguir. Vive-se numa escassez de liderança, por exemplo, no campo político, comunitário, familiar e educacional.

Em vista disso, o ambiente de trabalho, em todas as empresas, está cada vez mais apertado de competição, não se tolerando mais a acomodação, fato que faz com que os gestores e líderes não se deem conta de implementar um pensamento win-win. Mas o que é esse pensamento? Covey (2004 apud PINTO, 2011, p. 3) deixa assentado que existem duas dimensões interdependentes que dão suporte às relações win-win:

- Carácter - é a base das relações win-win, tudo se constrói à volta do carácter das pessoas envolvidas. O carácter é resultado de três aspectos essenciais: a integridade (a capacidade de fazer e cumprir promessas), a maturidade (o grau de desenvolvimento como pessoa) e a mentalidade da abundância (partir do princípio que há para todos, ou seja, que o ganho de uns não elimina a possibilidade de ganho dos outros);

- Relação - win-win é um modo de estar em que pessoas e organizações podem validar no decorrer das suas vidas, podem confirmar a sua validade e auferir os seus benefícios. É possível demonstrar que se ganhará mais ambicionando o que todos querem do que procurando apenas o que uma parte quer.

No âmbito da gestão de qualquer tipo de organização, é necessário tratar o cliente como se o gestor fosse o cliente. Da mesma forma, o colaborador deve ser tratado com respeito, bem como cada vez mais o jogo de cintura e a capacidade de se comunicar, de fazer várias tarefas e do espírito conciliador são exigidos no mundo do trabalho. Portanto, a relação winwin será o ponto de partida para que qualquer negociação seja bem-sucedida. Deve-se perder essa tendência ao maniqueísmo, de achar que existe o bom ou o ruim, ou é meu amigo ou é meu inimigo. Isso é um reducionismo. As relações precisam envolver um processo de negociação integrado e cooperativo no qual todos ganham, havendo um benefício mútuo entre as partes envolvidas.

Conforme mencionado alhures, o homem parentético é um indivíduo que procura agir eticamente levando em conta seus valores. Nesse passo, sua posição numa negociação remete 
à cooperação no lugar do confronto e da disputa, colaborando com o ambiente organizacional, não negando o benefício ao longo prazo.

Ao avançar com uma relação win-win (seja ela pessoal ou profissional), é
importante estar consciente de que, para colher os frutos desta, é necessário
um considerável investimento de confiança, honestidade e integridade por
parte daqueles envolvidos. O conceito win-win é simples e agradável pelos
benefícios que gera, contudo não é simples, é uma estratégia dura e exigente
que assenta na regra elementar (não fazer aos outros o que não gostaríamos
que fosse feito a nós). (PINTO, 2011, p. 4).

Ao ensejo da conclusão deste item, convém evidenciar que as organizações hoje colocaram em suas agendas a perspectiva da qualidade de vida e também a capacidade de interação entre seus colaboradores, levando em conta as relações interdependentes como forma de definir estratégias e alcançar os objetivos definidos pelo líder.

O gestor deve ter ações que levem a um processo de humanização dentro da instituição, nos espaços de trabalho, com uma gestão de pessoas que atraia e retenha os colaboradores com perfis parentéticos.

No hodierno, não é mais concebível, como era antigamente, o chefe que manda e o colaborador que fica calado, numa gestão verticalmente estruturada. O colaborar tem limites, e não é mais possível tratar o colaborador como "escravo".

Nesse sentido, as empresas que possuem uma boa gestão de pessoas procuram ouvir antropólogos, sociólogos e psicólogos para buscar o equilíbrio e o diálogo entre as gerações que existem no interior da instituição.

\section{CONSIDERAÇÕES FINAIS}

Orientar ações na área de gestão de pessoas é complicado. O objetivo deste artigo foi trazer à tona teorias e assuntos que estão em debate constantemente no mercado e no mundo do trabalho.

O mercado de educação superior não é diferente de outros mercados. Atualmente, a gestão de pessoas no interior das organizações está diretamente relacionada ao envolvimento dos colaboradores com os objetivos da empresa.

As pessoas e as empresas são interdependentes, e o colaborador deve ser visto como alguém que contribuiu para o sucesso da empresa. Nesse sentido, um simples obrigado e um bom dia são coisas simples que fazem bem a qualquer colaborador no seu dia a dia de 
trabalho e, sobretudo, a transparência na gestão contribui para a empresa e seus colaboradores se destacarem no mercado e no mundo do trabalho.

Não se está, aqui, de maneira alguma, defendendo que a relação entre empresa e colaborador seja totalmente amável, mas também não deve haver potencialmente perdedores ou ganhadores, ou seja, todos devem ganhar e é isso que as relações win-win buscam atingir.

Pessoas no lugar errado e com atitudes erradas podem prejudicar sensivelmente a empresa e o ambiente onde estiverem trabalhando. Não há mais espaço para atitudes politiqueiras, visto que quem age assim busca gerar um clima de competição e discórdia dentro da empresa.

A sociedade está cada vez mais se encaminhando em direção a estilos parentéticos de vida. Muitos indivíduos, acadêmicos e profissionais estão tentando "derrotar ou desestabilizar" os sistemas administrativos tradicionais, principalmente na tentativa de projetos de organizações não-hierárquicas e orientadas para a clientela, para órgãos e políticas voltadas para a proteção dos cidadãos e consumidores, bem como para o elevado crescimento de preocupações com questões da qualidade de vida humana no trabalho, preservação ambiental, autorrealização, desemprego, distribuição da riqueza e liberdade.

O caminho não é simples, exigindo de todos ações proativas, numa tentativa de escapar do fogo e da guerra interna que existe dentro de cada um. Várias pessoas têm muito, e outra grande quantidade nada tem. Também significa que muitas pessoas têm acesso a uma excelente educação, enquanto muitos milhões nunca irão à escola.

Nesse sentido, o Brasil está dando passos positivos na busca de uma educação de qualidade, mas falta muito, e o país tem ainda motivos para se envergonhar do que deixará para as gerações futuras. Assim, não se crê que essas gerações tolerarão esse conflito brutal, porque os governos precisam pôr em suas agendas que a desigualdade começa quando há uma educação diferente por ser rico ou pobre. Por isso, ninguém deve ser desprezado e todos devem receber educação para que não haja problemas no futuro. Isso é um elemento-chave: colocar a educação no mapa político de todo mundo, devendo haver educação para os ricos e para os pobres. Para todos. A educação não é um luxo, mas uma aspiração, como é também aspiração de todos os gestores que acreditam na educação, que empreendem neste setor, conseguir gerar um ambiente espiritual no sentido de que todos trabalhem com algum objetivo comum. Dessa forma, se terá, automaticamente, um ambiente onde a cultura e o espírito sejam coletivos, onde todos ganhem com o crescimento da instituição. 


\section{REFERÊNCIAS}

CARroll, J. D. Noetic authority. Public Administration Review, v. 29, p. 492-500, set./out. 1969.

CARDIM, Paulo A. Gomes. Os Caminhos Percorridos na Gestão Educacional e as suas Tendências. In: COLOMBO, Sonia Simões; CARDIM, Paulo A. Gomes. Nos bastidores da educação brasileira. Porto Alegre: Artmed, 2010. p. 23-35.

COLOMBO, Sonia Simões. A gestão de pessoas nas instituições de ensino. In: COLOMBO, Sonia Simões; CARDIM, Paulo A. Gomes. Nos bastidores da educação brasileira. Porto Alegre: Artmed, 2010. p. 169-184.

FURTADO, Celso. O longo amanhecer. São Paulo: Paz e Terra, 1999.

PINTO, João Paulo. As relações win-win: o pensamento certo no sucesso pessoal e empresarial. Disponível em:

$<$ http://www.leanthinkingcommunity.org/livros_recursos/artigo_relacoes_win-win.pdf.> Acesso em: 04 out. 2011.

RAMOS, Alberto Guerreiro. A ascensão do homem parentético. Tradução de Tânia Fischer e Mafalda Elisabeth Schmid. Salvador: Universidade Federal da Bahia, 1984.

SCHUMPETER, Joseph. A. Teoria do desenvolvimento econômico: uma investigação sobre lucros, capital, crédito, juro e o ciclo econômico. Tradução de Maria Silvia Possas. São Paulo: Abril Cultural, 1982.

SILVA, Everaldo da. Estudo da expansão do mercado de educação superior no Brasil e em Santa Catarina no período de 1995 a 2002. 2010. 264f. Tese (Doutorado em Sociologia Política) - Centro de Filosofia e Ciências Humanas, Universidade Federal de Santa Catarina, Florianópolis, 2010.

STEIBERG, Herbert; MARCATTI, Luiz. Governança corporativa aplicada às instituições de ensino. In: COLOMBO, Sonia Simões; CARDIM, Paulo A. Gomes. Nos bastidores da educação brasileira. Porto Alegre: Artmed, 2010. p. 267-283. 


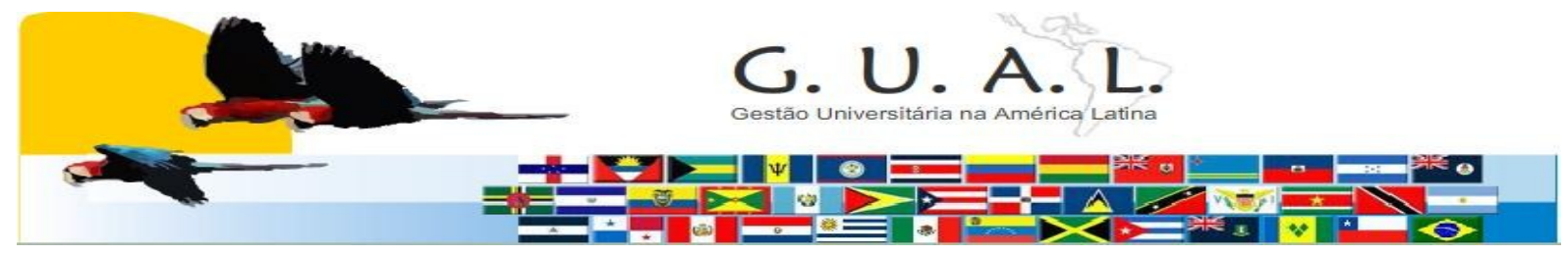

ISSN 1983-4535

\title{
PEOPLE AND EDUCATIONAL INSTITUTIONS MANAGEMENT: A POSITIVE-SUM EXERCISE
}

\author{
Marlon Jackson Tafner, Doctor \\ Associação Educacional Leonardo da Vinci - UNIASSELVI \\ marlon@grupouniasselvi.com.br \\ Everaldo da Silva, Doctor \\ Associação Educacional Leonardo da Vinci - UNIASSELVI \\ evesociologia@gmail.com
}

\begin{abstract}
For many people, winning means other's loss. It means that two or more parts compete in a fixed base where the winner gets the best part of it. This kind of relation is characterized for being hard, based on the price and not on the value. They are, thereby, adverse relations and do not promote the development of the parts. This article explores the many was of the relation among organizations approaching and, inevitable, among people, trying to embrace a different approach from the one used by the researches, university students and practitioners when they pore on the win-win relations among organizations. The considerations of the human-science-aspects results, combined with the best that the traditional approaches have to offer, may reveal themselves very important and renewable in the institute and the maintenance of the win-win relations.
\end{abstract}

Keywords: Management. College education. Win-win relation. Parenthetical man. 